\title{
Statutory retirement and changes in self-reported leisure-time physical activity: a follow-up study with three time-points
}

\author{
Ansku Holstila* (D), Minna Mänty, Ossi Rahkonen, Eero Lahelma and Jouni Lahti
}

\begin{abstract}
Background: Retirement is a key life event, which is associated with changes in physical activity, however, there is limited evidence with regard to changes in physical activity that take place in post-retirement years. The aim of this study was to examine how leisure-time physical activity changes shortly after the transition to retirement and during the post-retirement years.

Methods: The phase 1 data were collected in 2000-2002 ( $n=8960$, response rate 67\%) among 40-60-year-old employees of the City of Helsinki, Finland. Phase 2 was carried out in 2007 ( $n=7332$, response rate 83\%) and phase 3 in $2012(n=6814$, response rate 79\%). Disability retirees and those under the age of 50 at baseline were excluded. This yielded 2902 participants. Most of the participants (79\%) were women. The mean age of the participants was 54.4 in phase 1. Negative binomial models for repeated measurements with generalized estimating equations (GEE) were used to calculate the incidence rate ratios (IRR) and 95\% confidence intervals (CI). These indicated the changes in time spent in self-reported leisure-time physical activity among the retired compared with the continuously employed.
\end{abstract}

Results: Of the participants, 851 retired on the grounds of old age during the first period (phases 1-2), and 948 during the second period (phases 2-3). Change in physical activity was positive among those who retired during the first (IRR $=1.10,95 \% \mathrm{Cl} 1.04-1.17)$ and second (IRR $=1.10,95 \% \mathrm{Cl} 1.04-1.16)$ periods compared to the continuously employed. During the second period, there was little difference between those who had retired during the first one (IRR $=0.96,95 \% \mathrm{Cl} 0.91-1.02)$ and the continuously employed.

Conclusions: The transition to statutory retirement was associated with an immediate increase in leisure-time physical activity, which nevertheless diminished during post-retirement years.

Keywords: Exercise, Life-course transitions, Older adults, Employment status, Longitudinal study

\section{Background}

Physical inactivity is common worldwide especially among people in older age groups, and activity tends to decrease as people get older. Almost $50 \%$ of people 60 years and older are inactive in Europe [1,2]. Inactivity and low levels of activity among older people are especially harmful from a public-health perspective. Physical activity is necessary for healthy ageing as it reduces functional limitations [3], falls, risk of dementia as well as many other non-communicable diseases.

\footnotetext{
* Correspondence: ansku.holstila@helsinki.fi

Department of Public Health, University of Helsinki, P.O. Box 20, 00014 University of Helsinki, Helsinki, Finland
}

(c) The Author(s). 2017 Open Access This article is distributed under the terms of the Creative Commons Attribution 4.0 International License (http://creativecommons.org/licenses/by/4.0/), which permits unrestricted use, distribution, and reproduction in any medium, provided you give appropriate credit to the original author(s) and the source, provide a link to the Creative Commons license, and indicate if changes were made. The Creative Commons Public Domain Dedication waiver (http://creativecommons.org/publicdomain/zero/1.0/) applies to the data made available in this article, unless otherwise stated. associated with major life events and transitions, such as graduation, getting married, becoming a parent or retiring [4]. Previous studies have shown an association between the transition to statutory retirement and an increase in leisure-time physical activity [5-9]. However, there is still little evidence on whether post-retirement changes in physical activity are temporary or persistent. One study [10] with a 13-year follow-up showed no increase in leisuretime physical activity among retirees, indicating that the positive effect of retirement observed in other studies may be short-termed and may not be maintained postretirement. We are aware of only one study [11] which 
observed changes in physical activity also during the postretirement years and indicated that the increase in physical activity after transition to retirement is temporary.

It has been shown in previous studies, that changes in physical activity are also associated with socioeconomic position [12, 13], and with divorce, separation or the death of a spouse or a partner [9]. In addition, limiting longstanding illness, a high body mass index and smoking can cause a decline in the level of physical functioning [14-17], and thus limit opportunities to engage in physical activity. These factors should be taken into consideration in examining the association between the transition to retirement and changes in physical activity [7].

The present study continues our earlier research [7], which revealed a positive association between changes in leisure-time physical activity related to the transition to retirement but with only one follow-up after retirement. Our study focuses on two questions: (1) Is transition to statutory retirement associated with similar changes in leisure-time physical activity in two consecutive followup periods? (2) How does leisure-time physical activity change over the post-retirement period?

\section{Methods}

\section{Participants}

This study is based on Helsinki Health Study (HHS) cohort data. The baseline (phase 1) surveys were sent by mail to all employees of the City of Helsinki aged 40, 45, 50, 55 and 60 in 2000, 2001 and 2002. Phase 2 and phase 3 questionnaire surveys were conducted in 2007 and 2012 respectively. There were 8960 respondents in phase 1 (response rate $68 \%$ ), 7332 in phase 2 (response ate $83 \%$ ) and 6814 in phase 3 (response rate $78 \%)$. Seventy per cent $(n=6245)$ of the participants took part in all three surveys. Non-response and attrition analyses showed that the data sufficiently represent the target population [18]. Eighty per cent of the participants were women, which represents the gender distribution among municipal employees in Finland [19].

We included 2902 participants in our analysis, having excluded those who were under 50 years old in phase 1 $(n=3702)$ because there were only a few retirees in this age group. We excluded those who retired on special grounds such as disability $(n=731)$ because the association between retirement and changes in physical activity is likely to differ in disability compared with statutory retirement. We also excluded those who were outside employment due to other reasons than retirement during the follow up $(n=102)$ and those with missing values in physical activity variables, retirement status or other covariates $(n=266)$.

\section{Retirement status}

Retirement status was classified in three groups. Those who continued working during the entire follow-up time (continuously employed), those who retired in the first follow-up period between phase 1 and phase 2 (Retired1) and those who retired in the second follow up period between phase 2 and phase 3 (Retired2). Because we measured leisure-time physical activity for the whole of the preceding year we considered those who retired within six months of responding to the survey still to be in employment.

\section{The measurement of physical activity}

We used the same question to measure leisure-time physical activity (including commuting) in all three phases. The participants were asked how many hours a week, on average, they had spent on physical activity during the past year, on four grades of intensity equivalent to walking, brisk walking, running and jogging. The minutes spent on moderate to vigorous leisure-time physical activity were calculated by summing up the time spent on each intensity grade. The main analyses focused on the changes in time (minutes/week) spent on leisure-time physical activity. For descriptive purposes we calculated metabolic equivalent (MET) hours by multiplying the MET values of each intensity grade [20] and summing them up [21]. The participants were classified as low activity if their average weekly physical-activity level was less than 14 MET hours. The cut-off point of 14 MET -hours per week is based on the recommended level of physical activity, which is equivalent to approximately the energy expenditure $1000 \mathrm{kcal}$ per week. This level of physical is adequate to offset several risk factors of inactivity. [22].

\section{Covariates}

Gender, age, socioeconomic position (SEP) during phase 1 and time-variant marital status, smoking, limiting longstanding illness (LLI) and body mass index (BMI) were used as covariates. We dichotomized limiting longstanding illness (LLI) to those who reported a longstanding illness and that restricted working or other daily tasks and to those who did not. BMI was calculated by dividing the selfreported weight of the participants by their self-reported height in metres squared. Occupational socioeconomic position was classified in four groups: managers and professionals, semi-professionals, routine non-manual workers and manual workers. Marital status was classified as single, married or cohabiting, and divorced or widowed. Smoking status was divided into non-smokers and smokers based on self-reported regular smoking.

\section{Statistical methods}

We used comparison of means and cross tabulations to describe the study variables. Negative binomial regression models for repeated measurements with generalized estimating equations (GEE) were used to calculate the incidence rate ratios (IRR) and their 95\% confidence intervals (CI) for the changes in physical activity among the Retired1 and Retired2 groups compared with the continuously 
employed. Time in minutes per week was used as the outcome variable and the interaction between the phase and the retirement group was examined as a predictor. We adjusted the different covariates in three models. In the first model we adjusted for gender and age, in the second model also for SEP and time-variant marital status and the third for BMI and LLI, as well. There was no significant gender interaction $(p=0.2)$ and women and men were pooled for the analyses. We performed the analyses with SPSS version 22 for Windows.

\section{Results}

Table 1 presents the distributions of the study variables. The respondents were fairly evenly distributed by retirement status: 1108 were continuously employed, 851 retired during the first period between phases 1 and 2 (Retired1) and 948 retired during the second period between phases 2 and 3 (Retired2). The mean age of the participants was 54.4 years. The continuously employed were younger than the average age, and those in the Retired1 group were the oldest. There were slightly fewer routine non-manual workers in the Retired1 group than in the other groups. The proportion of smokers was highest among the continuously employed. A lower proportion of participants among the continuously employed reported limiting longstanding illness (LLI) during phase 1, but this difference almost disappeared during the follow-up. The proportion of inactive participants decreased in the Retired 1 group during the first period and increased during the second, and these changes were smaller among the continuously employed. The proportion of inactive members of the Retired2 group decreased during the first period, but there was no change during the second one. (Table 1).

The average amount of time spent on leisure-time physical activity in phase 1 was five hours and $15 \mathrm{~min}$ among the continuously employed, four hours and $59 \mathrm{~min}$ in the Retired1 group and five hours in the Retired2 group (Table 1; Fig. 1). During the first period the weekly amount of time being physically active increased by $30 \mathrm{~min}$ in the Retired1 group, changed very little among the continuously employed and increased in the Retired2 group, although less than in the Retired1 group. During the second period the average weekly time spent on leisure-time physical activity continued to increase in the Retired 2 group, with a mean change of nine minutes, but decreased by $20 \mathrm{~min}$ and $30 \mathrm{~min}$ among the continuously employed and those in the Retired1 group, respectively. (Fig. 1).

During the first period, physical activity increased significantly more (IRR $=1.10,95 \%$ CL 1.04-1.17) in the Retired1 group than among the continuously employed following adjustment for age and gender (Table 2). Further adjustments for socioeconomic position and marital status did not change the estimates, but smoking status, LLI and bodymass index attenuated the association slightly (IRR $=1.07$,
95\% CI 1.01-1.14). There was no difference in the change in time spent on physical activity between the Retired2 group and the continuously employed $(\mathrm{IRR}=1.04$, 95\% CI 0.98-1.11). (Table 2).

The increase in physical activity in the Retired2 group during the second period was not as notable as in the Retired1 group during the first period. There was also a decrease in physical activity among the continuously employed during the second period, however. Thus, the differences between the retired group and the continuously employed were similar during both periods (Table1 \& Fig. 1). Moreover, the age- and gender-adjusted relative difference in the changes in physical activity (IRR $=1.10$, 95\% CI 1.04-1.16) between the Retired2 group and the continuously employed was very similar during the second period to the difference between the Retired1 group and the continuously employed during the first period (Table 2). Adjustments for socioeconomic position and marital status did not change the associations. Adjusting for LLI and body-mass index again attenuated the association slightly $(\mathrm{IRR}=1.08,95 \%$ CI 1.02-1.14). The Retired 1 group reduced the time spent on physical activity more than the continuously employed during the second period (Fig. 1), but the difference was not statistically significant (IRR $=0.96,95 \%$ CI 0.91-1.02). (Table 2).

\section{Discussion}

Our results indicate a modest increase in leisure-time physical activity after the transition to statutory retirement, but this increase does not necessarily persist over a longer period. Retirement led to an immediate positive change in physical activity in both retirement groups compared to the continuously employed, although the increases in time were only 15 and $33 \mathrm{~min}$. The increase in physical activity at the time of retirement was larger in absolute numbers in the Retired1 than in the Retired2 group, but the relative difference from the continuously employed was similar. This similarity implies that the association between the transition to retirement and physical activity reported in our earlier study [7] was not attributable to a cohort effect, thus the increase in activity after retirement is not likely to relate to something that only affected employees in the Retired1 group. These results are consistent with findings from a review [6] indicating that the transition to retirement increases leisure-time physical activity.

The increase in leisure-time physical activity associated with the transition to retirement does not seem to persist. The higher activity level achieved after retirement reported in the present study was not maintained in that the time spent on leisure-time physical activity decreased among the Retired1 group over the years following retirement. However, members of this group maintained a similar level of activity as those in the continuously employed group, hence the increase in physical activity associated with the transition 
Table 1 Description of the study variables by retirement status $(N=2902)$

\begin{tabular}{|c|c|c|c|c|c|}
\hline & $\begin{array}{l}\text { Continuously employed } \\
n=1103\end{array}$ & $\begin{array}{l}{\text { Retired } 1^{a}}^{a} \\
n=851\end{array}$ & $\begin{array}{l}{\text { Retired } 2^{b}} \\
n=948\end{array}$ & $\begin{array}{l}\text { All } \\
n=2902\end{array}$ & $p x^{2} /$ Anova \\
\hline \multicolumn{6}{|l|}{ Phase 1.} \\
\hline Physical activity min/week mean (SD) & $315.0(206.5)$ & $299.1(195.8)$ & $299.9(192.3)$ & $305.4(198.9)$ & 0.126 \\
\hline Low activity \% & 22.8 & 26.6 & 26.3 & 25.0 & 0.088 \\
\hline Age mean(SD) & $51.0(2.14)$ & $58.5(2.35)$ & $54.9(1.80)$ & $54.4(3.72)$ & $<0.001$ \\
\hline Women \% & 81.1 & 75.7 & 81.3 & 79.6 & 0.004 \\
\hline Socio-economic position \% & & & & & 0.023 \\
\hline Managers and professionals & 35.1 & 38.2 & 37.5 & 36.2 & \\
\hline Semi-professionals & 16.0 & 18.8 & 17.4 & 17.3 & \\
\hline Routine non-manuals & 37.1 & 29.1 & 34.9 & 34.0 & \\
\hline Manuals & 11.9 & 13.9 & 12.0 & 12.5 & \\
\hline Marital status \% & & & & & 0.235 \\
\hline Single & 10.8 & 10.1 & 10.1 & 10.4 & \\
\hline Married or cohabiting & 70.2 & 73.0 & 68.8 & 70.5 & \\
\hline Divorced or widowed & 19.0 & 16.9 & 21.1 & 19.1 & \\
\hline Smokers \% & 22.3 & 14.0 & 18.6 & 18.6 & $<0.001$ \\
\hline BMI mean (SD) & $25.1(4.0)$ & $26.2(4.0)$ & $25.9(4.3)$ & $25.7(4.1)$ & $<0.001$ \\
\hline LLI \% & 12.1 & 21.2 & 17.6 & 16.5 & $<0.001$ \\
\hline \multicolumn{6}{|l|}{ Phase 2.} \\
\hline Physical activity min/week mean (SD) & $317.4(200.8)$ & $331.9(197.6)$ & $314.7(198.5)$ & $320.8(199.2)$ & 0.145 \\
\hline Low activity \% & 21.9 & 20.8 & 23.2 & 22.0 & 0.468 \\
\hline Marital status \% & & & & & 0.705 \\
\hline Single & 10.5 & 10.6 & 9.7 & 10.3 & \\
\hline Married or cohabiting & 66.3 & 68.6 & 67.6 & 67.4 & \\
\hline Divorced or widowed & 23.2 & 20.8 & 22.7 & 22.3 & \\
\hline Smokers \% & 17.3 & 11.3 & 14.7 & 14.7 & 0.001 \\
\hline BMI mean (SD) & $25.7(4.3)$ & $26.4(4.2)$ & $26.4(4.8)$ & $26.1(4.4)$ & 0.001 \\
\hline LLI \% & 24.5 & 25.0 & 28.5 & 29.5 & 0.092 \\
\hline \multicolumn{6}{|l|}{ Phase 3.} \\
\hline Physical activity min/week mean (SD) & $297.1(202.7)$ & $298.3(199.8)$ & $323.4(197.9)$ & $306.0(200.6)$ & 0.005 \\
\hline Low activity \% & 26.5 & 29.6 & 23.4 & 26.4 & 0.012 \\
\hline Marital status \% & & & & & 0.864 \\
\hline Single & 11.7 & 10.6 & 10.7 & 11.0 & \\
\hline Married or cohabiting & 63.2 & 64.9 & 65.2 & 64.3 & \\
\hline Divorced or widowed & 25.1 & 24.6 & 24.2 & 24.6 & \\
\hline Smokers \% & 14.3 & 8.3 & 11.3 & 11.4 & 0.001 \\
\hline BMI mean (SD) & $26.2(4.7)$ & $26.5(4.5)$ & $26.6(4.8)$ & $26.4(4.7)$ & 0.292 \\
\hline LLI \% & 27.6 & 29.5 & 27.3 & 28.0 & 0.053 \\
\hline
\end{tabular}

${ }^{\mathrm{a}}$ Retired between phase 1 and phase 2

${ }^{\mathrm{b}}$ Retired between phase 2 and phase 3

to retirement might partly even out the decrease associated with age. This is new evidence with regard to the association between the transition to retirement and leisure-time physical activity: several previous studies $[5,7,8]$ measured physical activity only once post-retirement and did not examine the changes during the following years. Our findings indicating changes during the post-retirement period are in accordance with the results of an earlier study [10] in which no association was found between the transition to retirement and changes in leisure-time physical activity over 


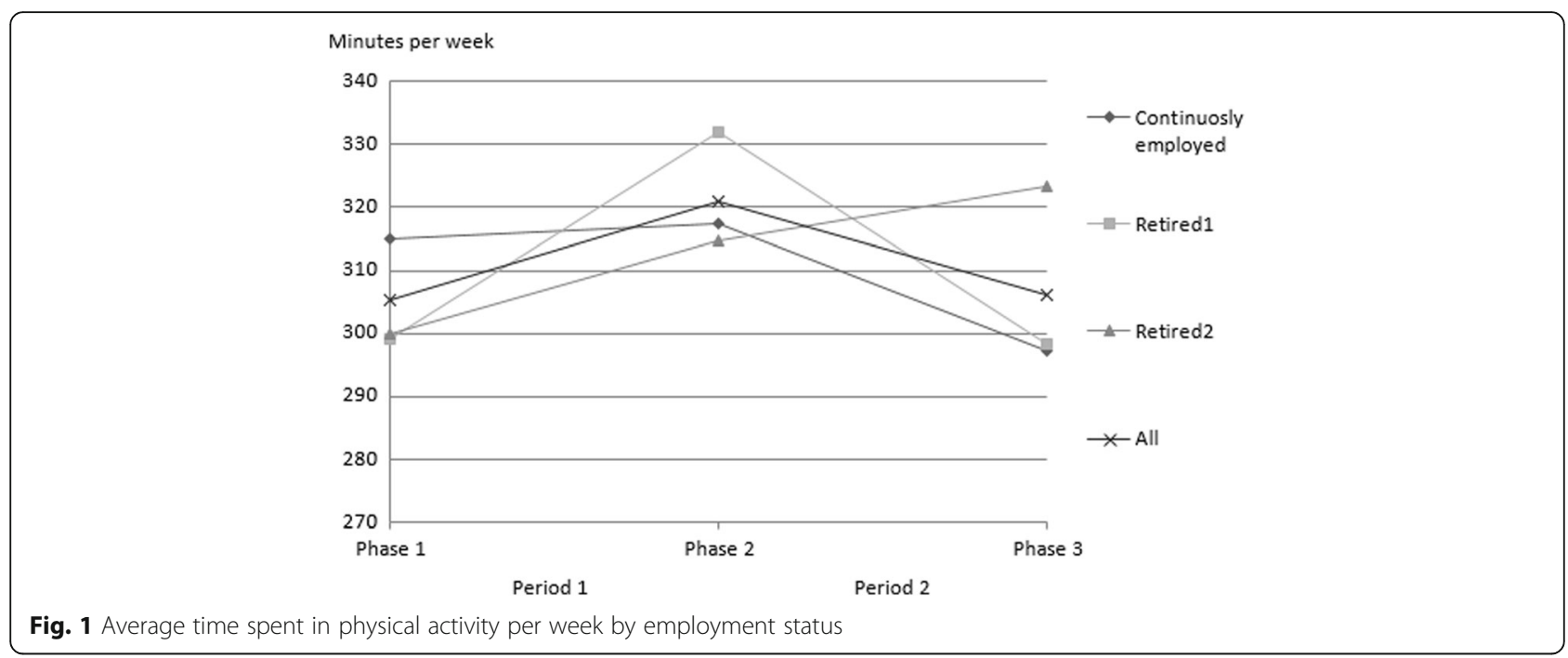

a long 13-year follow-up and another study [11] which found an increase in physical activity during the transition to retirement that even out during the post-retirement years.

One study [23] examined psychological well-being - before and after transition to retirement and found that recently retired men felt better about their ageing process than those who had been retired for longer than two years or those who were not yet retired. These findings imply that the phase shortly after transition to retirement may be psychosocially different from later phases during the post-retirement period, this maybe one reason why the increase in physical activity after transition to retirement is short - term.

The average level of leisure-time physical activity among the participants was high at around 300 min per week during phase 1 , thus the changes in time spent on such activity were quite modest in both absolute and relative terms. The

Table 2 The association between retirement status ( $N=2902)$ and change in time (min/week) spent on physical activity

\begin{tabular}{|c|c|c|c|c|c|}
\hline & \multirow{2}{*}{$\begin{array}{l}\text { Continuously employed } \\
\text { IRR }\end{array}$} & \multicolumn{2}{|c|}{ Retired1 } & \multicolumn{2}{|c|}{ Retired2 } \\
\hline & & $\mathrm{IRR}$ & $95 \% \mathrm{Cl}$ & IRR & $95 \% \mathrm{Cl}$ \\
\hline \multicolumn{6}{|l|}{ Period $1^{a}$} \\
\hline Model 1 & 1 & 1.10 & $(1.04-1.17)$ & 1.04 & $(0.98-1.11)$ \\
\hline Model 2. & 1 & 1.10 & $(1.04-1.17)$ & 1.04 & $(0.98-1.11)$ \\
\hline Model 3. & 1 & 1.07 & $(1.01-1.14)$ & 1.03 & $(0.97-1.09)$ \\
\hline \multicolumn{6}{|l|}{ Period $2^{\mathrm{b}}$} \\
\hline Model 1 & 1 & 0.96 & $(0.91-1.02)$ & 1.10 & $(1.04-1.16)$ \\
\hline Model 2. & 1 & 0.96 & $(0.91-1.02)$ & 1.10 & $(1.04-1.16)$ \\
\hline Model 3. & 1 & 0.95 & $(0.89-1.00)$ & 1.09 & $(1.02-1.15)$ \\
\hline
\end{tabular}

Model 1. Adjusted for age and gender

Model 2. Model 1. + SEP and marital status

Model 3. Model 2. + smoking, LLI and BMI

aPeriod 1 is the time-period between phase 1 and 2

${ }^{\mathrm{b}}$ Period 2 is the time-period between phase 2 and 3 changes in time spent in LTPA reported in other studies have varied. One study reported $2 \mathrm{~h}$ [8] increase and another around $30 \mathrm{~min}$ increase in physical activity [11]. In the present study the changes in the proportion of participants with low activity level $(<14$ MET-hours per week) were similar to the changes in time spent on physical activity. This implies that the increase in physical activity does not apply only to those who were highly active from the beginning, thus the changes are encouraging from the public-health perspective. Given the large proportion of retirees with low physical activity level in the older age group [1] and the fact that inactivity is one of the main risk factors for non-communicable diseases and disability [24], it would be ideal if the employees with low activity could become more active after the transition to retirement. However, an increase in physical activity is also likely to be beneficial to those who are already very active given the accumulating health benefits from engaging in up to five times the minimum recommended amount [25].

We focused only on leisure-time physical activity in this study. As work-related physical activity stops after retirement the total amount of physical activity may also decrease. One study [10] reported a decrease in overall physical activity after the transition to retirement, and another found an increase in total physical activity among people with sedentary jobs and a decrease among those with physically demanding jobs [26]. In addition, it should be noted that we examined the total time spent in leisure-time physical activity and separate analyses of moderate and vigorous activity was not included. Our previous study [7] showed that the level of vigorous activity was low among retirees and that the retirees increased moderate-intensity physical activity. However, it should be noted that for an older retiree the relative intensity of brisk walking may be as intense as jogging for a midlife employee. Thus it is important to examine the total amount of leisure-time physical activity. 


\section{Strengths and limitations}

Our question on physical activity included commuting physical activity, and the probable decrease in commuting physical activity after retirement is a potential cause of bias in our results. However, our findings are more likely to be conservative compared to studies that do not incorporate commuting activity, the loss of which after retirement counteracts the increases in leisure-time physical activity. Another limitation is that, we lack measurement of work related physical activity which is lost after retirement. Second, we used self-reported data on employment status and physical activity. It has been shown that self-reported measurements of physical activity may be overestimated. The questionnaire we used has not been validated, but similar questions have proved to be valid and reliable in comparison with a detailed interview [27]. Moreover, no other self-report questionnaire on physical activity has proved paramount [28]. Third, the age differences between the retirement status groups could have biased our results, given that age is associated with a decline in physical activity. We adjusted for age in our models but it had no effect on the associations. However, the age effect is likely to make our results more conservative because the increase in physical activity after retirement occurred among retirees, who were older than the continuously employed reference group used for comparison. Fourth, the cohort represent only municipal employees of the City of Helsinki which limits the generalisability of our findings.

The strengths of the study include the extensive, longitudinal, prospective dataset, and the fact that all the participants were employed and able to work during phase 1 . The longitudinal data collected at three time points enabled us to extend the evidence from previous studies by examining the changes in physical activity in post-retirement years as well as the change after the transition to retirement during the two consecutive follow-up periods.

\section{Conclusions}

Statutory retirement was associated with a short-term increase in leisure-time physical activity. However, the increase in leisure-time physical activity associated with retirement may slow down or delay the decrease in physical activity seen as people age. The results highlight the need not only to encourage people to increase their physical activity after retirement, but also to help retirees to maintain their physical activity levels in the longer term.

\section{Abbreviations \\ BMI: Body mass index; Cl: Confidence interval; GEE: Generalized estimating equations; IRR: Incidence rate ratio; LLI: Limiting longstanding illness; MET: Metabolic equivalent; SEP: Socioeconomic position}

\section{Acknowledgements}

We thank the members of the Helsinki Health Study research group, the City of Helsinki, and the participating employees and retirees.

\section{Funding}

This work was supported by the Academy of Finland [grant number: \#1294514 \#1257362]; the Ministry of Education and Culture [grant number: \#6303383]; the Juho Vainio foundation [grant number: \#4704095, \#4704897, \#4704084, \#4704484]; and the Finnish Work Environment Fund [grant number: \#112231, \#115182, \#116251].

\section{Availability of data and materials}

The data are kept at Department of Public Health, University of Helsinki,

Finland. The data can be shared upon agreement.

\section{Authors' contributions}

AH performed statistical analyses, interpreted results and drafted the manuscript. AH, MM, OR, EL and JL contributed to designing the study, interpreting results and drafting the manuscript. $A H, M M, O R, E L$ and $J L$ critically reviewed the manuscript and approved the final version.

\section{Competing interests}

The authors declare that they have no competing interests.

\section{Consent for publication}

Not applicable.

\section{Ethics approval and consent to participate}

The ethics committees of the Department of Public Health, University of Helsinki and the City of Helsinki have approved the Helsinki Health Study protocol. The confidentiality, anonymity, and data protection have been assured and the employees were informed that participating the survey is voluntary. The participants gave their consent when answering and returning the questionnaires.

\section{Publisher's Note}

Springer Nature remains neutral with regard to jurisdictional claims in published maps and institutional affiliations.

Received: 2 November 2016 Accepted: 21 May 2017

Published online: 30 May 2017

\section{References}

1. Hallal PC, Andersen LB, Bull FC, et al. Global physical activity levels: surveillance progress, pitfalls, and prospects. Lancet. 2012;380:247-57.

2. Jefferis BJ, Sartini C, Ash S, et al. Trajectories of objectively measured physical activity in free-living older men. Med Sci Sports Exerc. 2014; doi:10.1249/MSS.0000000000000410.

3. Keysor JJ. Does late-life physical activity or exercise prevent or minimize disablement?: a critical review of the scientific evidence. Am J Prev Med. 2003;25:129-36.

4. Corder K, Ogilvie D, van Sluijs EMF. Invited commentary: physical activity over the life course -whose behavior changes, when, and why? Am J Epidemiol. 2009; doi:10.1093/aje/kwp273.

5. Barnett I, van Sluijs E, Ogilvie D, et al. Changes in household, transport and recreational physical activity and television viewing time across the transition to retirement: longitudinal evidence from the EPIC-Norfolk cohort. J Epidemiol Commun H. 2014; doi:10.1136/jech-2013-203225.

6. Barnett I, van Sluijs E,M.F. and Ogilvie D. Physical Activity and Transitioning to Retirement: A Systematic Review. Am J Prev Med. 2012; 43: 329-336.

7. Lahti J, Laaksonen M, Lahelma E, et al. Changes in leisure-time physical activity after transition to retirement: a follow-up study. Int J Behav Nutr Phys Act. 2011;8:36.

8. Touvier M, Bertrais $\mathrm{S}$, Charreire $\mathrm{H}$, et al. Changes in leisure-time physical activity and sedentary behaviour at retirement: a prospective study in middle-aged French subjects. Int J Behav Nutr Phys Act. 2010;7:14.

9. Brown WJ, Heesch KC, Miller YD. Life events and changing physical activity patterns in women at different life stages. Ann Behav Med. 2009;37:294-305.

10. Slingerland AS, van Lenthe FJ, Jukema JW, et al. Aging, Retirement, and Changes in Physical Activity: Prospective Cohort Findings from the GLOBE Study. Am J Epidemiol. 2007;165:1356-63.

11. Stenholm S, Pulakka A, Kawachi I, et al. Changes in physical activity during transition to retirement: a cohort study. Int J Behav Nutr Phys Act. 2016;13:1. 
12. Mäkinen TE, Sippola R, Borodulin K, et al. Explaining educational differences in leisure-time physical activity in Europe: the contribution of work-related factors. Scand J Med Sci Sports. 2012;22:439-47.

13. Seiluri T, Lahti J, Rahkonen O, et al. Changes in occupational class differences in leisure-time physical activity: a follow-up study. Int I Behav Nutr Phys Act. 2011;8:1.

14. Laaksonen M, Rahkonen O, Martikainen P, et al. Smoking and SF-36 health functioning. Prev Med. 2006;42:206-9.

15. Woo J, Leung J, Kwok T. BMI, body composition, and physical functioning in older adults. Obesity. 2007;15:1886-94.

16. Mickle KJ, Steele JR. Obese older adults suffer foot pain and foot-related functional limitation. Gait Posture. 2015;42:442-7.

17. Giuli C, Papa R, Bevilacqua R, et al. Correlates of perceived health related quality of life in obese, overweight and normal weight older adults: an observational study. BMC Public Health. 2014;14:1.

18. Lahelma E, Aittomäki A, Laaksonen M, et al. Cohort profile: the Helsinki health study. Int J Epidemiol. 2013; doi:10.1093/ije/dys039.

19. Official Statistics of Finland (OSF): Employment [e-publication]. ISSN=2323-6825. Helsinki: Statistics Finland [referred: 26.5.2017]. Access method: http://www.stat.fi/ til/tyokay/index_en.html.

20. Kujala UM, Kaprio J, Sarna S, Koskenvuo M. Relationship of leisure-time physical activity and mortality: the finnish twin cohort. JAMA. 1998;279:440-4.

21. Ainsworth BE, Haskell WL, Whitt MC, et al. Compendium of physical activities: an update of activity codes and MET intensities. Med Sci Sports Exerc. 2000;32(Suppl 1):498-504.

22. Fogelholm M, Suni J, Rinne M, et al. Physical activity pie: a graphical presentation integrating recommendations for fitness and health. JPAH. 2005;

23. Kim JE, Moen P. Retirement transitions, gender, and psychological well-being: a life-course, ecological model. J Gerontol B Psychol Sci Soc Sci. 2002;

24. Beaglehole R, Bonita R, Horton R, et al. Priority actions for the noncommunicable disease crisis. Lancet. 2011;377:1438-47.

25. Loprinzi PD. Dose-response association of moderate-to-vigorous physical activity with cardiovascular biomarkers and all-cause mortality: considerations by individual sports, exercise and recreational physical activities. Prev Med. 2015;81:73-7.

26. Chung S, Domino ME, Stearns SC, et al. Retirement and physical activity: analyses by occupation and wealth. Am J Prev Med. 2009;36:422-8.

27. Waller K, Kaprio J, Kujala UM. Associations between long-term physical activity, waist circumference and weight gain: a 30-year longitudinal twin study. Int J Obesity. 2007;32:353-61.

28. van Poppel MM, Chinapaw MM, Mokkink L, et al. Physical activity questionnaires for adults. Sports Med. 2010;40:565-600

\section{Submit your next manuscript to BioMed Central and we will help you at every step:}

- We accept pre-submission inquiries

- Our selector tool helps you to find the most relevant journal

- We provide round the clock customer support

- Convenient online submission

- Thorough peer review

- Inclusion in PubMed and all major indexing services

- Maximum visibility for your research

Submit your manuscript at www.biomedcentral.com/submit

C) Biomed Central 